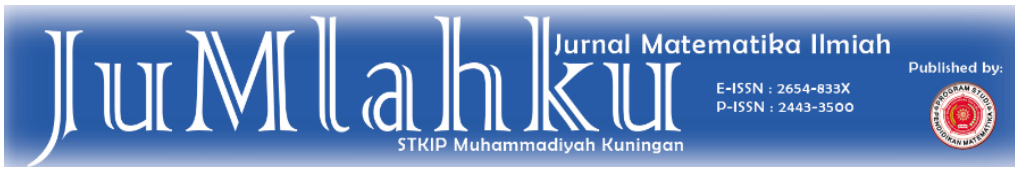

Submited: 2021-01-15

Published: 2021-11-28

\title{
PERBANDINGAN MODEL PEMBELAJARAN INQUIRY DAN MODEL PEMBELAJARAN RELATING, EXPERIENCING, APPLYING, COOPERATING, AND TRANSFERING TERHADAP PEMAHAMAN MATEMATIS
}

Aditya Reinaldo ${ }^{a)}$, Thamrin Tayeb ${ }^{\text {b) }}$, Fitriani Nurc), Suhartid), Munawarahe)

a,b,c,d Pendidikan Matematika, Fakultas Tarbiyah dan Keguruan, UIN Alauddin Makassar

e Pendidikan Matematika, Fakultas Tarbiyah, IAIN Bone

Corresponding Author : aditya.reinaldho@gmail.com a)

thamrin.thayeb@uin-alauddin.ac.id b)

fitrianinur@uin-alauddin.ac.id c)

suharti.harti@uin-alauddin.ac.id d)

munawarahr@gmail.com ${ }^{\mathrm{e}}$

\begin{tabular}{|c|c|}
\hline Article Info & Abstract \\
\hline $\begin{array}{l}\text { Keywords : Inquiry, } \\
\text { REACT, and students' } \\
\text { mathematical } \\
\text { understanding. }\end{array}$ & $\begin{array}{l}\text { This study aims to determine the differences between students' } \\
\text { ' mathematical understanding who are taught using the Inquiry } \\
\text { learning model and the REACT learning model. This type of } \\
\text { research is a quasi-experimental (Quasi Experimental) design } \\
\text { with Nonequivalent Control Group Design which was } \\
\text { implemented at SMP Negeri } 5 \text { Pitfeedua, Wajo Regency. Data } \\
\text { collection techniques using test techniques and analyzed using } \\
\text { descriptive statistical analysis. Based on the results of data } \\
\text { analysis, the pretest and posttest results of students who were } \\
\text { taught with the Inquiry learning model obtained an average } \\
\text { pretest score of } 47.50 \text { in the medium category and an average } \\
\text { posttest score of } 65.00 \text { in the high category. The results of the } \\
\text { pretest and posttest students who were taught with the REACT } \\
\text { learning model obtained an average pretest score of } 51.00 \text { in the } \\
\text { medium category and an average posttest score of } 71.67 \text { in the } \\
\text { high category. That is, there is a difference between the } \\
\text { mathematical understanding of students who are tauaht usina }\end{array}$ \\
\hline
\end{tabular}


the Inquiry learning model and the mathematical understanding of students who are taught using the REACT.

Kata

Inquiry, REACT, pemahaman matematis siswa.
Kunci: Penelitian ini bertujuan untuk mengetahui perbedaan dan antara pemahaman matematis siswa yang diajar menggunakan model pembelajaran Inquiry dan model pembelajaran REACT. Jenis penelitian ini yaitu eksperimen semu (Quasi Experimental) dengan desain Nonequivalent Control Group Design yang dilaksanakan di SMP Negeri 5 Pitumpanua Kabupaten Wajo. Teknik dan instrumen pengumpulan data menggunakan tes dan dianalisis menggunakan analisis statistik deskriptif. Berdasarkan hasil analisis data diperoleh hasil pretest dan posttest siswa yang diajar dengan model pembelajaran Inquiry diperoleh nilai rata-rata pretest sebesar 47,50 pada kategori sedang dan nilai rata-rata posttest sebesar 65,00 pada kategori tinggi. Hasil pretest dan posttest siswa yang diajar dengan model pembelajaran REACT diperoleh nilai rata-rata pretest sebesar 51,00 pada kategori sedang dan nilai rata-rata posttest sebesar 71,67 pada kategori tinggi. Artinya, terdapat perbedaan antara pemahaman matematis siswa yang diajar dengan menggunakan model pembelajaran Inquiry dengan pemahaman matematis siswa yang diajar dengan menggunakan model pembelajaran REACT.

\section{PENDAHULUAN}

Kata dasar Pendidikan ialah didik, lalu diberi awalan "me" jadi "men-didik", maksudnya merawat sekaligus melatih. Ketika merawat juga melatih maka perlu pengajaran, penuntunan, serta pimpinan tentang budi pekerti dan kecerdasan. Mendidik berarti memberikan peningkatan dan pengembangan (to elicit to give rise to; and to evolve to develop) (Mustofa, 2015: 6). Pendidikan ialah suatu perilaku sadar yang dilakukan dengan memanfaatkan berbagai sarana dan prasarana yang menunjang untuk proses pendewasaan aspek kognitif , psikologi dan afektif siswa ke arah yang lebih baik. Adanya pendidikan dapat memaksimalkan segala bakat yang dimiliki oleh seseorang.

Pemahaman konsep merupakan unsur penting dalam pembelajaran matematika (Gilmore et al., 2018: 2; Huda, Anggraini, Saputri, Syazali, \& Umam, 2019: 173). Dalam pembelajaran saat di kelas, mengerti akan konsep sangatlah dibutuhkan 
peserta didik sebab konsep ini termasuk medium penghubung subyek penahu (peserta didik) dan obyek. Pemahaman konsep harus dimiliki siswa guna mengerti sintaks dalam pembelajaran matematika (Rochaminah \& Anggraeni, 2016: 697) karena konsep matematika saling berhubungan (Zevika, Yarman, \& Yerizon, 2012: 47). Pentingnya pemahaman matematis terpaparkan di dalam tujuan belajar matematika yakni memahami suatu konsep, memaparkan kaitan antar konsep serta pengaplikasiannya dengan akurat, tepat, dan efisien ketika memecahkan suatu kasus (Prastika, Djalil, \& Asnawati, 2013: 2). Tak hanya itu saja, tujuan mempelajari konsep matematika ialah guna melakukan pemecahan masalah. Hal sejalan dengan pendapat Minarni, Napitupulu, dan Husein (2016: 1) bahwa pemahaman matematis adalah bagian integral dari pemecahan masalah matematika, sementara pemecahan masalah adalah jantung dari melakukan matematika. Pemahaman konseptual lazimnya dapat diartikan kemampuan para siswa menguasai suatu konsep, menyatakannya dengan kalimat sendiri, dan dapat menghubungkannya dengan peristiwa nyata (Eriana, Kartono, \& Sugianto, 2019: 2).

Pemahaman konsep dalam diri peserta didik dapat mempengaruhi pencapaian prestasi belajar yang diperoleh peserta didik (Oktaviana, Eka, \& Rohendi, 102
2017: 4). Pemahaman matematika siswa adalah hal yang sangat diperlukan sebab dengan tahu kemampuan para siswa, guru juga jadi tahu kesulitan yang mereka hadapi (Ramdhani, Usodo, \& Subanti, 2017: 3). Beberapa masalah yang membutuhkan pemahaman konsep matematika tetapi belum belum optimal akan menyebabkan lemahnya pemahaman satu konsep dengan konsep lain yang diperlukan saat menyelesaikan masalah matematika (Kariadinata, Yaniawati, Sugilar, \& Riyandani, 2019: 2). Untuk itu, diperlukan suatu tindakan yang mendukung hasil belajar siswa khususnya pada pemahaman matematis siswa.

Point penting yang mendorong hasil belajar matematika seorang siswa ialah model pembelajaran. Model pembelajaran adalah suatu cara yang dibentuk untuk kegiatan belajar mengajar yang berpatokan pada tujuan, sintaks, lingkungan, dan manajemen pembelajarn kelas (Nurhadi, Surachmi, \& Utaminingsih, 2020: 2). Pemakaian model pembelajaran dan media yang akurat serta sesuai akan dapat memaksimalkan penyampaian guru, namun jika model yang dipakai tidak akurat maka hasil belajar juga tidak maksimal, akan ada rasa keterpaksaan dan ketidaknyamanan dari siswa saat mengikuti kegiatan pembelajaran.

Berdasarkan hasil interview dengan salah seorang guru matematika di SMPN 5 
Pitumpanua Kabupaten Wajo menyatakan bahwasanya siswa tampak sulit mengerti materi matematika sehingga menyebabkan rendahnya pemahaman matematis siswa. Ini sejalan dengan pengakuan seorang siswanya bahwa mereka menganggap matematika itu sulit untuk dipahami. Hal ini berdampak terhadap kurangnya pengetahuan mereka tentang materi yang sedang diberikan. Karenanya solusi yang dapat diberikan yaitu dengan menggunakan model pembelajaran seperti model Inquiry dan Model REACT (Relating, Experiencing, Applying, Cooperating, and Transfering).

Menurut Djuanda dan Maulana (2015: 46) Inquiry merupakan rantaian kegiatan belajar yang menitik beratkan dalam berpikir kritis serta analitis dalam menemukan juga mencari sendiri jawaban masalah yang ditanyakan. Sementara menurut Israwani (2015: 57) model Inquiry melatih para siswa agar selalau berpikir dengan kritis dan analisis, sehingga dapat mengerti akan suatu konsep dengan rinci tetapi juga tetap menghargai pendapat yang lain. Inquiry ialah runtutan kegiatan belajar mengajar yang difokuskan pada keaktifan para siswa dalam mempunyai pengalaman belajar mendeteksi berbagai konsep dari masalah yang diberikan (Suhada, 2017: 3). Inkuiri adalah proses pembelajaran aktif yang didorong oleh pertanyaan dan pemikiran kritis. Pemahaman yang dikembangkan siswa melalui inkuiri lebih dalam dan lebih tahan lama daripada pengetahuan yang dikemas sebelumnya yang disampaikan oleh guru kepada siswa (Wonkyi \& Adu, 2016: 6). Lingkungan belajar dengan model pembelajaran inkuiri mendukung penambahan hasil belajar siswa (Wen et al., 2020: 3).

Model pembelajaran Inquiry menekankan kepada pengembangan aspek kognitif, afektif, dan psikomotorik secara seimbang (Daryanto, 2010: 34). Dengan gaya belajar mereka serta dapat melayani kebutuhan peserta didik yang memiliki kemampuan di atas rata-rata. Hal ini sejalan dengan pendapat Pratiwi, Sujana, dan Jayadinata (2017: 293) bahwa melalui model pembelajaran Inquiry, maka kegiatan belajar jadi terasa bermakna dan juga melekat dipikiran para siswa sebab mereka diberi peluang untuk mencoba, mengalami, serta melakukan sendiri, jadi bukan hanya mendengar apa yang disampaikan tetapi terlibat aktif dalam kegiatan tersebut, guru jadi tidak sekedar memindahkan ilmu. Melalui berbagai sintaks dari model pembelajaran Inquiry dapat diciptakan suatu kondisi pembelajaran yang dapat memungkinkan para siswa memperoleh kebebasan menyampaikan ide, pertanyaan, serta masalah, jadi belajar akan efektif (Yanda, Jumroh, \& Octaria, 2019: 3). Dengan begitu, di dalam model ini para siswa tidak hanya diharapkan menguasai materi tetapi juga memanfaatkan potensi mereka masing- 
masing (Arifuddin, Alfiani, \& Hidayati, 2018: 5). Ketiga aspek dalam model pembelajaran ini dirancang secara seimbang (Putri, 2018: 23).

Tujuan utama dari model pembelajaran Inquiry yaitu memajukan kemampuan siswa berpikir kritis melalui beberapa sintaks yakni orientasi, merumuskan masalah, membuat hipotesis, mengumpulkan data, menganalisis data, menguji hipotesis, dan menyimpulkan (Rumiyati, 2018: 19). Melalui pembelajaran dengan menggunakan model pembelajaran Inquiry akan bermanfaat untuk menghadapi dan menyelesaikan permasalahan di kehidupannya yang dapat mempengaruhi aktivitas dalam belajar (Suwanto, Wachidi, \& Turdja'i, 2017: 8). Dalam pembelajaran inkuiri, guru berperan sebagai mentor dalam pengambilan keputusan (Matthew \& Kenneth, 2013: 136; Obomanu \& Dorathy, 2014: 238). Dalam proses inkuri, guru dan siswa bekerjasama dalam memformulasikan masalah dan mengembangkan jawaban (Mulyana, Rusdi, \& Vivanti, 2018: 106).

Selain model Inquiry, model pembelajaran yang mampu mengasah keterampilan berpikir adalah model REACT. Model pembelajaran REACT memberi peluang untuk siswa agar belajar mengalami bukan menghafal, memakai konsep, dan melatih keterampilan berpikir mereka dengan optimal (Kurniawan, Tegeh, \& Suartama, 2014: 3). Model pembelajaran REACT ialah 104 model yang dapat menolong guru agar siswa dapat menanamkan suatu konsep (Yulianti, 2008: 26). Siswa akan diminta mendeteksi sendiri suatu konsep yang dipelajari, bekerjasama, dan menggunakan konsep itu dalam kehidupan mereka sekaligus mengubahnya dalam kondisi yang baru. Oleh karena itu, model REACT ini masuk dalam rencana pembelajaran yang memacu para siswa membuat berbagai hubungan antara penerapan di kehidupan nyata dengan pengetahuan yang mereka punya (Ul-Khoiriyah, 2019: 2). Selain itu, melalui proses menghubungkan antara pengalaman langsung dan yang telah lalu, peserta didik diprediksi dapat bernalar dengan lebih baik (Agusti, 2020: 2). Model pembelajaran REACT berada di bawah pemahaman pembelajaran konstruktivisme yang menitik beratkan bahwasanya pengetahuan dibentuk dan dibangun dalam benak para siswa, serta model ini menekankan makna pembelajaran (Nagari, Nuraini, \& Nuris, 2019: 4).

Relating (mengaitkan) ialah belajar dalam artian pengalaman kehidupan nyata ataukah pengetahuan terdahulu. Experiencing (mengalami) ialah strategi dalam belajar melalui explorasi, menemukan, serta mencipta. Berbagai pengalaman di kelas bisa mulai penggunaan yang manipulatif, kegiatan pemecahan masalah, juga laboratorium. Applying (menerapkan) ialah belajar dengan 
mendudukkan berbagai konsep untuk digunakan, yakni dengan pemberian Latihan yang relevan serta realistic. Cooperating (bekerjasama) ialah belajar dalam artian saling sharing, merespon, dan berkomunikasi dengan pelajar lain. Kemudian Transferring (mentransfer) ialah kondisi belajar yang memakai pengetahuan di konteks/kondisi yang baru (Anas \& Fitriani A, 2018: 4).

Model pembelajaran REACT memandang perlu bagi siswa turut serta berpartisipasi di berbagai kegiatan. Siswa diarahkan guru untuk mengerjakan kegiatan relating (mengaitkan) antara materi yang telah dan akan dipelajari. Setiap tim diberi kasus permasalahan untuk melakukan eksplorasi pada kasus itu, disajikan (tahap experiencing). Beberapa soal yang dapat diselesaikan dengan pemakaian konsep baru yang mereka dapat (tahap applying), serta beberapa soal baru (tahap transferring). Kemudian ketika berdiskusi siswa membentuk sifat bekerjasama (tahap cooperating) dan meningkatkan kemampuan siswa berkolaborasi dengan yang lain dalam menyelesaikan permasalahan (Ambarwati, Zein, \& Rahmi, 2019: 2).

Model pembelajaran REACT menitikberatkan dipemberian informasi yang ada kaitannya dengan informasi terdahulu yang mereka kuasai, jadi siswa akan lebih mudah mengetahui konsep yang disampaikan guru karena sering didapati di kehidupan nyata (Kusumaningsih, Sutrisno, \& Hidayah, 2019: 3). Kegiatan pembelajaran menggunakan model REACT dapat memberikan ruang siswa memahami, merencanakan, menyelenggarakan, dan memeriksa lagi hasil dari pekerjaannya. Dalam model pembelajaran ini para siswa diberikan permasalahan sehari-hari agar dihubungkan dengan konsep yang baru akan dipelajari. Diskusi memberikan kesempatan siswa mengeksplor, mencari, menemukan, dan mengaplikasikan materi. Kegiatankegiatan ini dapat meningkatkan kemampuan matematis mereka khususnya kemampuan koneksi dan representasi.

Dari pemaparan di atas diselenggarakanlah penelitian untuk membandingkan mengenai model pembelajaran Inquiry dan model pembelajaran REACT (Relating, Experiencing, Applying, Cooperating, Transfering).

\section{METODE}

Penelitian yang diselenggarakan ini termasuk dalam jenis eksperimen semu (Quasi Experimental). Peneliti menggunakan 2 tim yakni tim eksperimen 1 dan tim eksperimen 2. Tujuannya guna melihat perbedaan pemahaman matematis siswa antara kedua tim ini yang masing-masing mengaplikasikan model pembelajaran inquiry dan REACT (Relating, Experiencing, Applying, Cooperating, and Transfering). 
Penelitian ini menerapkan Nonequivalent Control Group Design. Dalam desain ini ada 2 tim eksperimen yang diberikan perlakuan (Sugiyono, 2012: 118).

Populasi penelitiannya ialah semua siswa di kelas VIII SMPN 5 Pitumpanua ini dengan menggunakan sampel jenuh. Sebagai tim eksperimen 1 (tim yang mengaplikasikan model pembelajaran Inquiry) adalah kelas VIII.1 dan tim eksperimen II (tim yang mengaplikasikan model pembelajaran $R E A C T$ ) adalah kelas VIII.2. Teknik dan istrumen penelitian menggunakan tes, dan dianalisis menggunakan statistik deskriptif. Analisis statistik deskriptif digunakan untuk mendeskripsikan dan mengetahui perbedaan pemahaman matematis siswa yang didapat siswa baik itu di tim eksperimen 1 maupun tim eksperimen 2 .

\section{HASIL DAN PEMBAHASAN}

Dari tes pemahaman matematis peserta didik yang diberikan kepada siswa kelas VIII.1 SMP Negeri 5 Pitumpanua Kabupaten Wajo sebelum dan sesudah pembelajaran dengan model pembelajaran Inquiry yang sudah diproses menggunakan SPSS versi 20 dengan hasil seperti tabel di bawah ini:
Tabel 1

Nilai Statistik Dekriptif Hasil Pretest dan Posttest Kelas VIII.1

\begin{tabular}{ccc}
\hline Statistik & \multicolumn{2}{c}{ Nilai } \\
\cline { 2 - 3 } Jumlah sampel & Pretest & Posttest \\
Nilai terendah & 40 & 20 \\
Nilai tertinggi & 65 & 45 \\
Nilai rata-rata & 47,50 & 85 \\
Standar deviasi & 8,192 & 11,000 \\
Nilai Varians & 67,105 & 121,053 \\
\hline
\end{tabular}

Berdasarkan tes pemahaman matematis siswa yang diberikan kepada peserta didik kelas VIII.2 SMP Negeri 5 Pitumpanua Kabupaten Wajo sebelum dan sesudah pembelajaran dengan model pembelajaran REACT yang telah diproses menggunakan SPSS versi 20 dengan hasil seperti tabel berikut:

\section{Tabel 3}

Nilai Statistik Dekriptif Hasil Pretest dan Posttest Kelas VIII.2

\begin{tabular}{ccc}
\hline Statistik & \multicolumn{2}{c}{ Nilai } \\
\cline { 2 - 3 } & Pretest & Posttest \\
Jumlah sampel & 15 & 15 \\
Nilai terendah & 40 & 60 \\
Nilai tertinggi & 65 & 85 \\
Nilai rata-rata & 51,00 & 71,67 \\
Standar & 9,673 & 9,386 \\
deviasi & & \\
Nilai Varians & 93,571 & 88,095 \\
\hline
\end{tabular}


Variasi pemahaman konsep antara siswa kelas percobaan 1 dan siswa kelas percobaan 2 digunakan hasil analisis statistik deskriptif yaitu dengan membandingkan nilai rata-rata pemahaman konsep kedua kelas tersebut. Rata-rata pemahaman konsep peserta didik kelas percobaan 1 dan peserta didik kelas percobaan 2 ditampilkan pada tabel berikut:

Tabel 5

Nilai Rata-Rata Pemahaman Konsep

\begin{tabular}{cc}
\hline Kelas & $\begin{array}{c}\text { Nilai Rata-Rata } \\
\text { Pemahaman Konsep }\end{array}$ \\
\hline Eksperimen 1 & 65,00 \\
Eksperimen 2 & 71,67 \\
\hline
\end{tabular}

Dari Tabel 5, dapat dilihat bahwa ratarata pemahaman konsep peserta didik kedua kelas tersebut berbeda yaitu kelas percobaan 1 yaitu 65,00 dan kelas percobaan 2 yaitu 71,67. Jadi, ada perbedaan pemahaman matematis peserta didik yang diajar menggunakan model pembelajaran Inquiry dengan pemahaman matematis peserta didik yang diajar dengan model REACT (Relating, Experiencing, Applying, Cooperating, and Transfering) pada siswa kelas VIII SMP Negeri 5 Pitumpanua Kabupaten Wajo. Inquiry adalah aktifitas pembelajaran dimana peserta didik terlibat dalam proses penyelidikan. Sedangkan, model pembelajaran REACT merupakan bentuk pembelajaran yang dapat menunjang guru dalam membentuk konsep pada peserta didik. Peserta didik diajak bekerja sama, menerapkan model tersebut pada kehidupan hari-hari dan mengirim pada kondisi baru (Yulianti, 2008: 60). Perbedaan dari kedua model tersebut dapat terlihat melalui tahapannya masing-masing. Model pembelajaran Inquiry terdiri atas 6 (enam) tahapan yaitu (1) Orientasi, (2) Merumuskan masalah, (3) Mengajukan hipotesis, (4) Mengumpulkan data, (5) Menguji hipotesis, dan (6) Merumuskan kesimpulan. Sedangkan, model pembelajaran REACT (Relating, Experiencing, Applying, Cooperating, and Transfering) terdiri dari 6 (enam) tahapan yaitu (1) Relating (mengaitkan), (2) Experiencing (mengalami), (3) Applying (menerapkan), (4) Cooperating

(bekerjasama),

Cochran (2007: 23) yang mengatakan keuntungan pembelajaran inkuiri untuk peserta didik dapat memperdalam ilmu akan gagasan matematika, karena disaat belajar peserta didik masuk dalam kegiatan yang mengarahkan mereka dalam mengkonstruksi serta memahami konsep apa yang dipelajari dan dengan berdiskusi ia dapat berkomunikasi dengan aktif sehingga memperoleh penguatan pengetahuan matematika peserta didik.

Menurut Israwani (2015: 57) bentuk pembelajaran inkuiri membentuk peserta didik berpikir kritis dan analisis, sehingga dapat memahami konsep ataupun materi secara baik dan rinci tetapi tetap 
mengutamakan sikap saling menghargai opini masing-masing. Jadi, penggunaan model Inquiry dalam pembelajaran dapat meningkatkan pemahaman matematis siswa.

Novri, Zulfah, dan Astuti (2018: 88) bahwa penerapan model REACT pada pelajaran matematika dapat melatih siswa agar mengembangkan kemampuan memahami konsep matematisnya. Hal tersebut karena dalam pembelajaran menggunakan REACT siswa diwajibkan agar memahami konsep dalam permasalahan yang diberikan guru serta menghubungkannya dengan pengalaman dan pengetahuan awal siswa. Pembelajaran bukan hanya mengenai konsep dari guru, tetapi siswa aktif membentuk pengetahuannya melalui bimbingan oleh guru. Dalam pembelajaran dengan model REACT, siswa juga memperoleh pengetahuan dari kegiatan menemukan yang dilakukan tidak hanya melalui transfer ilmu dari guru ke siswa (Jannah, Supardi, \& Prabowo, 2020: 158).

Menurut Kurniawan et al. (2014: 7) bahwa bentuk pembelajaran REACT memfasilitasi ruang kepada peserta didik untuk belajar merasakan proses bukan hanya menghafal, mencoba konsep, dan mengasah keterampilan berpikir peserta didik dengan optimal. Jadi, penggunaan model REACT (Relating, Experiencing, Applying, Cooperating, and Transfering) 108 pada pembelajaran dapat menaikkan pemahaman matematis peserta didik. Hal ini sejalan dengan pendapat yang menyatakan REACT efektif dalam peningkatan hasil belajar siswa (Latifah, Komikesari, \& Ulum, 2017: 107).

\section{PENUTUP}

\section{Simpulan}

Dari analisis pendataan yang diperoleh pada pretest dan posttest peserta didik menggunakan bentuk pembelajaran Inquiry diperoleh nilai rata-rata pretest yaitu 47,50 pada kategori sedang dan nilai ratarata posttest yaitu 65,00 pada kategori tinggi. Hasil pretest dan posttest peserta didik menggunakan model pembelajaran REACT diperoleh nilai rata-rata pretest yaitu 51,00 pada kategori sedang dan nilai rata-rata posttest yaitu 71,67 pada kategori tinggi. Artinya, ada perbedaan pemahaman matematis peserta didik menggunakan model pembelajaran Inquiry dibandingkan pemahaman matematis siswa yang diajar dengan menggunakan model pembelajaran REACT pada siswa kelas VIII SMP Negeri 5 Pitumpanua Kabupaten Wajo

\section{Saran}

Dari hasil temuan yang telah dipaparkan peneliti merekomendasikan untuk lebi memperdalam lagi hasil penelitian dengan memperhatikan variabel-variabel 
psikologi maupun menvariasikan beberapa sintaks dari kedua model tersebut.

\section{DAFTAR PUSTAKA}

Agusti, F. A. (2020). Pengaruh Model Pembelajaran REACT terhadap Kemampuan Penalaran Matematis Peserta Didik Kelas VIII SMP Negeri 2 Payakumbuh. Jurnal Edukasi Dan Penelitian Matematika, 9(1), 51-56.

Ambarwati, S. S., Zein, M., \& Rahmi, D. (2019). Pengaruh Penerapan Model Pembelajaran REACT (Relating, Experiencing, Applying, Cooperating, Transferring) terhadap Kemampuan Komunikasi Matematis berdasarkan Self Efficacy Siswa Sekolah Menengah Pertama Negeri 8 Pekanbaru. JURING: JOurnal for Research in Mathematics Learning, 2(4), 317-324.

Anas, A., \& A, F. (2018). Penerapan Model Pembelajaran REACT dalam Peningkatan Pemahaman Konsep Siswa. Al-Khwarizmi: Jurnal Pendidikan Matematika Dan IImu Pengetahuan, 6(2), 157-166. https://doi.org/https://doi.org/10.2425 6/jpmipa.v6i2.338

Arifuddin, A., Alfiani, D. A., \& Hidayati, S. (2018). Pengaruh Model Pembelajaran Inkuiri Terhadap Kemampuan Pemecahan Masalah Matematika Siswa Kelas IV Madrasah Ibtidaiyah. Al-Ibtida: Jurnal Pendidikan Guru MI, 5(2), 261-274. https://doi.org/http://dx.doi.org/ 10.24235/al.ibtida.snj.v5i2.3374
Cochran, R. (2007). The Impact of InquryBased Mathematics on Context Knowledge and Classroom Practice.

Daryanto. (2010). Belajar dan Mengajar. Bandung: CV Yrama Widya.

Djuanda, D., \& Maulana. (2015). Ragam Model Pembelajaran di Sekolah Dasar. Sumedang: UPI Sumedang Press.

Eriana, Kartono, \& Sugianto. (2019). Understanding Ability of Mathematical Concepts and Students' Self-reliance towards Learning by Implementing Manipulative Props (APM) on Jigsaw Technique. Journal of Primary Education, 8(2), 176-183.

Gilmore, C., Clayton, S., Cragg, L., McKeaveney, C., Simms, V., \& Johnson, S. (2018). Understanding arithmetic concepts: The Role of Domain-Specific and Domain-General Skills. PLOS ONE COLLECTION Education Research, 1-20. https://doi.org/https://doi.org/10.1371/ journal.pone.0201724

Huda, S., Anggraini, L., Saputri, R. D., Syazali, M., \& Umam, R. (2019). Learning Model to Improve the Ability to Understand Mathematical Concepts. Jurnal PRISMA Universitas Suryakancana, 8(2), 173-181.

Israwani. (2015). Penggunaan Model Pembelajaran Inkuiri Pada Materi Operasi Hitung Bilangan di Kelas I SD Negeri 53 Banda Aceh. Jurnal Peluang, 3(2), 55-64.

Jannah, M., Supardi, Z. A. I., \& Prabowo. (2020). Guided Inquiry Model with the REACT Strategy Learning Materials 
to Improve the Students' Learning Achievement. IJORER: International Journal of Recent Educational Education, 1(2), 156-168.

Kariadinata, R., Yaniawati, R. P., Sugilar, H., \& Riyandani, D. (2019). Learning Motivation and Mathematical Understanding of Students of Islamic Junior High School Through Active Knowledge Sharing Strategy. Infinity Journal, 8(1), 31-42.

Kurniawan, I., Tegeh, I. M., \& Suartama, I. K. (2014). Pengaruh Strategi Kontekstual REACT terhadap kinerja Pemecahan Masalah IPA Siswa SMP Negeri 6 Singaraja. Jurnal Edutech UNDIKSHA, 2(1), 1-10. https://doi.org/http://dx.doi.org/10.238 87/jeu.v2i1.3582

Kusumaningsih, W., Sutrisno, \& Hidayah, F. (2019). Efektivitas Model Pembelajaran SAVI dan React Berbantuan LKS terhadap Kemampuan Komunikasi Matematis Siswa SMP. Journal of Medives: Journal of Mathematics Education IKIP Veteran Semarang, 3(2), 197207.

https://doi.org/https://doi.org/10.3133 1/medivesveteran.v3i2.763

Latifah, S., Komikesari, H., \& Ulum, M. (2017). Efektivitas strategi REACT (Relating, Experiencing, Applying, Cooperating, Transfering) terhadap Hasil Belajar dan Keterampilan Proses Sains di SMPN 22 Bandar Lampung. Jurnal Penelitian Pembelajaran Fisika, 8(2), 101-108. Matthew, B. M., \& Kenneth, I. O. (2013). A 110
Study On The Effects Of Guided Inquiry Teaching Method On Students Achievement In Logic. International Researcher, 2(1), 135-140.

Minarni, A., Napitupulu, E. E., \& Husein, R. (2016). Mathematical Understanding and Representation Ability of Public Junior High School in North Sumatra. Journal on Mathematics Education, 7(1), 43-46.

Mulyana, S., Rusdi, \& Vivanti, D. (2018). The Effect of Guided Inquiry Learning Model and Scientific Performance on Student Learning Outcomes. IJOSE: Indonesian Journal of Science and Education, 2(1), 105-109. https://doi.org/10.31002/ijose.v2i1.59

Mustofa, B. (2015). Psikologi Pendidikan. Yogyakarta: Parama IImu.

Nagari, P. M., Nuraini, U., \& Nuris, D. M. (2019). A Case Study: The Application of REACT Learning Model in Accounting Education. International Journal of Education, Psychology and Counseling, 4(24), 30-37.

Novri, U. S., Zulfah, \& Astuti. (2018). Pengaruh Strategi REACT (Relating, Experiencing, Applying, Cooperating, Transfering) Terhadap Kemampuan Pemahaman Konsep Matematis Peserta Didik Kelas VII SMP Negeri 1 Bangkinang. Jurnal Cendekia: Jurnal Pendidikan Matematika, 2(2), 81-90.

Nurhadi, M., Surachmi, S., \& Utaminingsih, S. (2020). Pengaruh Model Pembelajaran Inquiry terhadap Hasil Belajar Siswa Materi Operasi Hitung Bilangan Cacah di Kelas VI Sekolah Dasar. VIVABIO: Jurnal Pengabdian 
Multidisiplin, 2(1), 44-60.

Obomanu, N. J., \& Dorathy, E. (2014).

Relative Effect of Two Forms of Pedagogy on Secondary School Students Performance in Ecology Concepts in Rivers State. International Journal of Education and Research, 2(10), 237-250.

Oktaviana, Eka, S., \& Rohendi, E. (2017). Model Brain Based Learning (BBL) untuk Meningkatkan Pemahaman Siswa pada Konsep Daur Air. Antologi UPI, 5(1), 1-7.

Prastika, N., Djalil, A., \& Asnawati, R. (2013).

Pengaruh Pendekatan Kontekstual (CTL) Terhadap Pemahaman Konsep Matematis Siswa. Jurnal Pendidikan Matematika, 1(3), 1-11.

Pratiwi, C. O., Sujana, A., \& Jayadinata, A. K. (2017). Penerapan Model Pembelajaran Inkuiri untuk Meningkatkan Hasil Belajar Siswa Kelas V pada Materi Pesawat Sederhana. Jurnal Pena IImiah, 2(1), 291-300.

Putri, N. (2018). Studi Komparatif Metode Guided Inquiry Learning dan Metode Problem Based Learning terhadap Kemampuan Berpikir Kritis Siswa. Indonesian Journal of Economic Education, 1(1), 17-30.

Ramdhani, M. R., Usodo, B., \& Subanti, S. (2017). Student's mathematical understanding ability based on selfefficacy. Journal of Physics: Conference Series, Series 909, 1-7.

Rochaminah, S., \& Anggraeni. (2016). Perancangan Model Pembelajaran Sesuai Tuntutan Kurikulum 2013
Untuk Meningkatkan Pemahaman Konsep dan Keterampilan Berpikir Mahasiswa Calon Guru Matematika. Prosiding Seminar Nasional Matematika \& Pendidikan Matematika (SENDIKA), 2(2), 695-701.

Rumiyati, C. N. (2018). Pengaruh Model Pembelajaran Inquiri terhadap Hasul Belajar SIswa Kelas IV SD pada Muatan Pelajaran Matematika tentangb FPB. Universitas Sanata Dharma Yogyakarta.

Sugiyono. (2012). Metode Penelitian Kombinasi (Mixed Methods). Bandung: Alfabeta.

Suhada, H. (2017). Model Pembelajaran Inquiry dan Kemampuan Berpikir Kritis terhadap Keterampilan Proses Sains Siswa Kelas $V$ pada Mata Pelajaran IPA. Jurnal Pendidikan Dasar, 8(2), 1-8.

Suwanto, Wachidi, \& Turdja'i. (2017). Penerapan Model Pembelajaran Inkuiri untuk Meningkatkan Berpikir Logis dan Prestasi Belajar (Studi Pada Mata Pelajaran Matematika Kelas V Di SDN 03 Gugus 1 Kabupaten Bengkulu Utara). DIADIK: Jurnal IImiah Teknologi Pendidikan, 7(2), 141-154.UI-Khoiriyah, A. (2019). Penerapan Strategi REACT untuk Meningkatkan Pemahaman Siswa pada Pembelajaran Matematika. Al-Aulad, 2(1), 1-9.

Wen, C.-T., Liu, C.-C., Chang, H.-Y., Chang, C.-J., Chang, M.-H., Chiang, S.-H. F., ... Hwang, F. (2020). Students' Guided Inquiry with Simulation and Its Relation to School Science 
Achievement Andscientific Literacy. ScienceDirect Procedia -Social and Behavioral Sciences, 149.

Wonkyi, T., \& Adu, E. (2016). Effect of The Inquiry-Based Teaching Approach on Students' Understanding of Circle Theorems in Plane Geometry. African Journal of Educational Studies in Mathematics and Sciences, 12, 1-9.

Yanda, K. O., Jumroh, \& Octaria, D. (2019).

No Title. INDIKTIKA (Jurnal Inovasi Pendidikan Matematika), 2(1), 58-67. https://doi.org/10.31851/indiktika.v2i1 .3428

Yulianti, L. (2008). Model-model Pembelajaran Fisika. Universitas Negeri Malang: Lembaga Pengembangan Pembelajaran.

Zevika, M., Yarman, \& Yerizon. (2012). Meningkatkan Kemampuan Pemahaman Konsep Siswa Kelas VIII SMP Negeri 2 Padang Panjang Melalui Pembelajaran Kooperatif Tipe Think Pair Share Disertai Peta Pikiran. Jurnal Pendidikan Matematika, 1(1), 45-40. 